\title{
RELATIONS OF SOME PERSONALITY TRAITS AND CHARACTERISTICS OF SPORTSMEN WITH THE LEVEL OF SPORTS ANXIETY
}

\author{
Dejana Velikić ${ }^{1}$ Jasmina Knežević ${ }^{1}$, and Nadežda Rodić ${ }^{1}$ \\ ${ }^{1}$ College of Professional Studies for the education of teachers and coaches, Subotica, Serbia
}

\section{SUMMARY}

Sports anxiety, as a kind of anxiety, drives a tendency to evaluate the competition situations as threatening, and in response to this situation, there is an anxious state. As the previous research results show the link between anxiety levels and achievement, research problem is whether there is a connection between the personality traits of athletes with a degree of anxiety in athletes, as well as whether there are differences in the level of anxiety in relation to sex of athletes, type of sports and the level of success in sport. The goal of this research is to improve understanding of the personal and situational factors associated with anxiety in athletes. The starting point was the multidimensional theory of anxiety that distinguishes somatic component of anxiety, cognitive component and confidence. The study included 90 athletes who were asked to judge the degree of sports anxiety using the CSAI-2 scale and personality traits $(\mathrm{VP}+2)$. The findings confirm the personality traits as predictors of somatic anxiety, with the aggressiveness being a significant predictor of somatic anxiety. Neuroticism, openness and aggressiveness emerged to be the predictors of cognitive anxiety and conscientiousness, openness and aggressiveness as predictors of sport confidence..

Key Words: multidimensional theory of anxiety, personality traits, sports anxiety.

\section{INTRODUCTION}

Sports results prove us every day that physical competence and readiness of the sportsman`s body are not sufficient factors for sucess in sporting activities. Equaly important, if not even more, are numerous psychological factors such as: personal characteristics, self-confidence, sports anxiety etc. According to these premises, the aim of this research is to improve the understanding of personal and situational factors which are strongly connected with the sports anxiety. Determining such connections between anxiety and sports achievements has been the topic of a great number of researches (Feltz, 1988; Gould, Petlichkoff, \& Weinberg, 1984; Martens, Burton, Vealey, Bump, \& Smith, 1990). Weinberg and Gould define anxiety as a negative emotional state which is characterized by nervousness, uneasiness, worries, as well as the activation and arousing the body to be in the state of alert (Weinberg \& Gould, 1996; according to Pineda-Espejel, López-Walle, Rodríguez, Villanu- eva, \& Gurrola, 2011). In the context of a sporting competition a certain amount of anxiety appears, the so-called competitive anxiety. In the case of sports anxiety it is necessary to distinguish two dimensions: the sports anxiety as a state of mind and body from the sports anxiety as a personal characteristic. Martens defines the traits of sports anxiety as a tendency to judge the competing situations as threatening where the anxient state of the body is the right response to such a situation (Martens, 2007; according to Behzadi, Hamzei, Nori, \& Salehian, 2011). The state of sports anxiety refers to the emotional state of fear, tension in a concrete sporting event (Vujanović \& Tišma, 2011). Researches clearly show the continual high level of sports anxiety as a disturbing influence which lessens the sportsman`s overall achievement. (Behzadi et al., 2011; Craft, Magyar, Beckern, \& Feltz, 2003; Pineda-Espejel et al., 2011). In a great number of researches, anxiety was viewed as an occurrence with a single dimension, however, Martens et al. (1990) point out that sports anxiety has several diffe- 
rent dimensions, it is actually multidimensional. In accordance with such a statement, the same authors establish the multidimensional theory of anxiety. This theory underlines the fact that anxiety includes somatic and cognitive components as well as self-confidence. The somatical anxiety refers to the body symptoms which are detected with a sportsman (faster heart beat, sweating of palms, pain in muscles, etc.). The cognitive anxiety is the mental component of anxiety and it develops from the negative expectations and lack of self-confidence and doubts on ableness and aptness of the body (Pineda-Espejel et al., 2011). Most commonly, the cognitive anxiety and worries are often recognized as the key or main element of sports anxiety (Bridges \& Knight, 2005; Dunn \& Dunn, 2001). The cognitive anxiety is mostly and mainly oriented towards the future, it appears when the attention is focused onto the expected sources of danger, in one word, the potential failure (Bridges \& Knight, 2005; Dunn \& Dunn, 2001; Humara, 1999). By expecting fiasco, the sportsman focuses his attention onto the things he can not accomplish, onto his imperfections but not onto his own real potentials and abilities. In that way it is hard for the sportsman to remain calm, "cool as a cucumber" in most crucial situations. Researches show a negative link between the cognitive anxiety and high sporting results (Hardy \& Carce, 2009; Humara, 1999). The lack of sports self-esteem, although not the direct measure of anxiety, makes the cognitive anxiety even bigger and more threatening. The higher sports self-esteem, the better results. Thus, that bond is positive, but on the other hand, the higher somatic anxiety bears lower sporting results and can be shown and explained by the upside curve of the letter $U$ (Humara, 1999).

The sports achievement requires a certain level of body readiness and aptness; that level should not be too high or too low because it will have negative effects onto the sports results. The researchers were examining the impact of the somatic and cognitive anxiety onto the sports achievements. When the cognitive anxiety is low, the physiological readiness has no impact onto the achievement (Ibid). However, as the cognitive anxiety rises, the physiological readiness may have positive or negative effects onto the achievements, depending on the level of challenge the body responds promptly (Ibid). As it was expected, the higher level of excitement had negative impact onto the achievement. The self-esteem has an important role in achieving good results, if you deeply believe in your own skills and abilities, you will perform well. If there is no such faith but doubts which prevail, the sportsman will have the feeling that the task is far too hard for him, beyond his potentials (Hardy \& Crace, 2009). Experience has great influence onto the level of cognitive anxiety, especially the length of time spent on training. The more experienced sportsmen report about lower level of cognitive anxiety contrary to the higher level of sport self-confidence (Humara, 1999). The researches clearly show important influence of sports self-esteem onto the achievements, it is much bigger than anxiety. The leading, top athletes have some advantages when it comes to feeling cognitive anxiety, since their self-esteem, which is strong, serves as a protective factor (Hardy, 1996). It is obvious and evident from the researches that there is a lot of difference between the sportsmen who perform in individual and team sports. The higher level of somatic anxiety together with the lower self-esteem is found and confirmed with the sportsman who practice individual sports, compared to those who play team, collective sports (Humara, 1999; Kirby \& Liu, 1999). The explanation for this is simple. In a sports team the resposibility is devided, all the players share it whereas in an individual sport the sportsman takes the resposibility all by himself (Humara, 1999), in regard to a different referential frame of these sportsmen (team versus individual frame). We find similar results if we compare sportsmen and sportswomen. Women, in general, have a lower level of self-esteem while they have a higher level of somatic and cognitive anxiety when compared to men. These results can be easily explained if we take into account the fact that women, unlike men, have more doubts about themselves and their abilities (Humara, 1999; Pineda-Espejel et al., 2011). The cognitive and somatic anxiety of men are connected with the estimated skills of the rival and his chance to win. On the other hand, the cognitive anxiety and sports self-esteem of women are deeply rooted with their preparation for the contest and the meaning of their winning (Jones, Swain, \& Cale, 1991).

Personal traits also greatly contribute to anxiety. Personal predispositions, which are mostly mentioned as a basis of emotional reactions (anxiety is among them), are extroversion and neuroticism (Marić, 2010). Neuroticism is strongly linked to negative affectation, refering to tendency towards experiencing negative emotions, including anxiety as well (Marić, 2010; Tran, 2012). Positive feelings and optimism are deeply tied with extroversion. Extroversive people have a low level of cognitive diligence so they are in need of more stimulii, which results in even greater behavioral activity (Smederevac, Mitrović, \& Čolović, 2010). On the other hand, introvert people are on the opposite side and they tend to express conversely behavi- 
our and affectation (Knežević, Radović, \& Opačić, 1997; Marić, 2010; Smederac et al., 2010). Furthermore, introverts characterize a high level of cognitive readiness so they tend to avoid exaggerated stimulation all of which causes behavioral inhibitions (Smederac et al., 2010). Researches show that the combination of much neuroticism and less extroversion is the basic prerequisite of general anxiety, the fear of failure and depression on the sample of students (Gershuny \& Sher, 1998; Komarraju, Karau, \& Schmeck, 2009; Matsudaira \& Kitamura, 2006; Middeldorp et al., 2006). Taking the above mentioned premises into consideration, it may be expected that the similar combination of personal traits will appear with the sportsmen who show, demonstrate a higher level of sports anxiety. Conscientiousness appears to be a negative predictor of sports anxiety (Matsumoto, Takeuchi, Nakajima, \& Iida, 2000); sportsmen with outstanding conscientiousness are far more persistent in training which gives them more self-confidence and less anxiety. Neuroticism acts in the similar way, but in the opposite direction. Its consequence is a lower level of self-confidence whereas the level of anxiety is rather high. The researches show the connection of extroversion and self-confidence which together form the predictors of sports achievements (Matsumoto et al., 2000).

In accordance with the previously statements, the problem of this research is defined in the forms of questions: whether there was a connection between the personality traits of athletes with a degree of their anxiety as well as if there were differences in the level of anxiety in relation to the gender of athletes, the type of sports and the level of success in a certain sport.

If we consider the results of the above mentioned researches, the basic suppositions of this work are as follows: (1) Personality traits of athletes are significant predictors of sports anxiety. Expressive neuroticism with a low level of extroversion and conscientiousness are important predictors of somatic and cognitive anxiety. The inverse proportion of personal characteristics, less neuroticism and more extroversion with consciencessness, are connected with sports self-confidence. (2) There are significant differences in sports anxiety according to the gender of athletes. Women tend to have a lower level of sports self-confidence while they have a higher level of cognitive and somatic anxiety compared to men. (3) There are also differences in the presence of sports anxiety based on the type of sport, that is, whether it is an individual or a collective sport. The higher degree of the somatic anxiety and lower sports self-confidence is expected with the sportsmen enrolled in individual sports. (4) There are important and unavoidable differences in the presence of sports anxiety in relation onto the sports achievements, success. Outstanding athletes show a higher level of self-confidence and at the same time a lower degree of cognitive and somatic anxiety compared to ordinary sportsmen and recreative athletes.

\section{METHODES}

\section{Sample of entity}

The sample of this research were sportsmen from Subotica, $62.2 \%$ men and $37.8 \%$ women; the athletes who filled out the questionnaire were members of 17 sports clubs. The age of the sportsmen was from 14 to 55 years old (Table 1 ).

\section{Sample of varibales}

In this research we distinguish independent, predictory variables: a) demographic characteristics of the tested athletes (their gender, age, type of sport, judgement of the level of sports success) and b) personality traits and the Criterion variables such as: the cognitive anxiety, somatic anxiety and self-confidence.

\section{TABLE 1}

Sample of examinees.

\begin{tabular}{lcccccccr}
\hline \multicolumn{1}{c}{ Sex } & $n$ & $\begin{array}{c}\text { Average } \\
\text { age }\end{array}$ & $\begin{array}{c}\text { Type of } \\
\text { sport }\end{array}$ & $n$ & $\%$ & $\begin{array}{c}\text { Level of sport } \\
\text { performance }\end{array}$ & $n$ \\
\hline Men & 56 & 21.55 & Collective & 48 & 53.33 & Outstanding athletes & 15 & 16.67 \\
\hline Women & 34 & 19.32 & Individual & 42 & 46.67 & Ordinary athletes & 60 & 66.67 \\
\hline & & & & & & Recreative athletes & 15 & 16.67 \\
\hline Total & 90 & 20.71 & & 90 & 100.00 & & 90 & 100.00 \\
\hline
\end{tabular}

Legend: $\mathbf{n}$ - Number of respondents; $\%$ - Percentage; 


\section{Testing procedures}

The research was done in cooperation with 17 sports clubs. The researchers had visited 20 sports clubs in Subotica and explained to their leaderships the nature and the aim of this research. After the received agreement of 17 sports clubs, the second visit was arranged when the athletes interested in the research were given the testing materials. The testing sheets consist of the front page with main information on the research (who leads the research and what its main goal is), data on the usage of the results and the names and conntacts of the authors of this research. The registration for the testing was done collectively in the presence of the researchers.

For the purposes of this study, two instruments were used: Competitive State Anxiety Inventory-2 and (CSAI-2) (Martens et al., 1990) which consist of 27 items (not at all, just a little, medium, too much). The test has got three subscales: Cognitive anxiety $(9$ items) which refer to expecting a negative outcome, failure; Somatic anxiety (9 items) regarding the reactions of the athlete s body prior to the sports performance and Sports self-confidence (9 items) which measure the believes, faith in the skills athletes have on themselves.. The coefficients of the reliability of the scales: Cognitive anxiety $-\alpha=.83$, Somatic anxiety $-\alpha=.86$, Sports anxiety $-\alpha=.85$. The Test Measuring the Big Five Personality Factors Plus Two (VP+2) by the authors Smederevac et al. (2010). The test consists of 184 items with a five-degree scale of Likert's type of answers. There are seven great scales in the test - Neuroticism (35 items), Extroversion (24 items), Conscientiousness (28 items), Aggressiveness (30 items), Openness (20 items), Negative Valence (22 items) and Positive Valence (25 items). Each of these scales has got two or three subdimensions. The scale was created for those older than 18 years of age, so the younger athletes were excluded from the testing. In further analysis, as a measure of expressed traits, the factor scores were used for the first main components of seven above mentioned scales. The coefficients of the reliability of the scales are as follows: neuroticism $-\alpha=.88$, extraversion $-\alpha=.87$, conscientiousness $-\alpha=.63$, aggressiveness $-\alpha=.74$, openness $-\alpha=.78$, positive valence $-\alpha=.78$, negative valence $\alpha=.80$. The List of Demographic Characteristics - a part of the test refers to the: gender of athletes, their age, type of sport (individual/collective), their personal judgement of the level of sports success (outstanding, average and recreative sportsmen)

\section{Statistic Analysis}

The statistic analyses used in this survey are: descriptive statistics, multivariant analysis of variations and manifold regressive analysis.

\section{RESULTS}

\section{Personal traits as predictors of competitive anxiety}

Bearing in mind all the above mentioned and trying to seek for the answers onto the question wether the personal traits (neuroticism, extroversion, conscientiousness, aggressiveness, openness to new experience, negative valence and positive valence) are significant predictors of somatic anxiety, cognitive anxiety and sports self-confidence, the obtained data was examined and analyzed by the Manifold Regressive

\section{TABLE 2}

Importance of personal traits as predictors of somatic anxiety.

\begin{tabular}{lcrr}
\hline & $\beta$ & $t$ & \multicolumn{1}{c}{$p$} \\
\hline Neuroticism & -.013 & -.099 & .922 \\
\hline Positive valence & .148 & 1.147 & .257 \\
\hline Conscientiousness & .046 & .353 & .726 \\
\hline Extroversion & -.022 & -.171 & .865 \\
\hline Aggressiveness & -.468 & -3.579 & .001 \\
\hline Openness & .210 & 1.634 & .109 \\
\hline Negative valence & .052 & .398 & .692 \\
\hline \multicolumn{4}{r}{$\mathrm{R}=.529 ; \mathrm{R}^{2}=.279 ; F=2.493 ; p<.05$}
\end{tabular}

Legend: $\beta$ - Beta standardized partial contribution; $\mathbf{t}$ - Student's t distribution; $\mathbf{p}$ - Probability; $\mathbf{R}$ - Coefficient of multiple correlation; $\mathbf{R}^{2}$ - Coefficient of determination; $\mathbf{F}$ - Fisher's test of determining statistical singificance. 
TABLE 3

Importance of personal traits as predictors of cognitive anxiety.

\begin{tabular}{lrrr}
\hline & $\beta$ & \multicolumn{1}{c}{$t$} & \multicolumn{1}{c}{$p$} \\
\hline Neuroticism & .250 & -.043 &. $\mathbf{0 3 3}$ \\
\hline Positive valence & -.005 & -1.698 & .966 \\
\hline Conscientiousness & -.193 & .742 & .096 \\
\hline Extroversion & .086 & -3.887 & .462 \\
\hline Aggressiveness & -.448 & 2.101 & $\mathbf{. 0 0 0}$ \\
\hline Openness & .237 & -.054 & $\mathbf{. 0 4 1}$ \\
\hline Negative valence & -.006 & 2.198 & .957 \\
\hline \multicolumn{2}{r}{$\mathrm{R}=.665 ; \mathrm{R}^{2}=.442 ; F=5.085 ;$} & $p<.05$
\end{tabular}

Legend: $\beta$ - Beta standardized partial contribution; $\mathbf{t}$ - Student's t distribution; $\mathbf{p}$ - Probability;

$\mathbf{R}$ - Coefficient of multiple correlation; $\mathbf{R}^{2}$ - Coefficient of determination; $\mathbf{F}$ - Fisher's test of determining statistical singificance.

\section{TABLE 4}

Importance of personal traits as predictors of sports self-confidence.

\begin{tabular}{|c|c|c|c|}
\hline & $\beta$ & $t$ & $p$ \\
\hline Neuroticism & .117 & .996 & .325 \\
\hline Positive valence & .120 & 1.028 & .310 \\
\hline Conscientiousness & .246 & 2.100 & .041 \\
\hline Extroversion & .017 & .142 & .888 \\
\hline Aggressiveness & .327 & 2.757 & .008 \\
\hline Openness & -.379 & -3.260 & .002 \\
\hline Negative valence & .080 & .673 & .504 \\
\hline
\end{tabular}

Legend: $\beta$ - Beta standardized partial contribution; $\mathbf{t}$ - Student's t distribution; $\mathbf{p}$ - Probability;

$\mathbf{R}$ - Coefficient of multiple correlation; $\mathbf{R}^{2}$ - Coefficient of determination; $\mathbf{F}$ - Fisher's test of determining statistical singificance.

Analysis. The analyzed data was obtained by athletes who were older than 18 years ( 69 athletes of full age). The results of this study show that personal traits are important predictors of somatic anxiety (Table 2), cognitive anxiety (Table 3) and sports self-confidence (Table 4). The personal traits explain $28 \%$ variances of somatic anxiety, $44 \%$ variances of cognitive anxiety and $40 \%$ variances of sports self-confidence.

\section{Gender differences in the presence of sports anxiety (cognitive and somatic anxiety and sports self-confidence)}

Of course, the study has provided abundant examples and data confirming the thesis that there are gender differences in the presence of sports anxiety with athletes and it was examined by means of Multifold Analysis of Variations (Table 5). The results show a great difference in the level of anxiety where women express much more cognitive anxiety $M_{w}=19.82$ compared to men $M_{m}=17.06$.

\section{Differences in Expressing Sports Anxiety in Relation to the Type of Sport (individual/collective)}

The analysis of the results, depending on the type of sport, whether it is a collective or individual, give us the following findings. Athletes who train an individual sport have much more somatic anxiety than those who practice collective sports $A\left(M_{i}=19.28\right.$; $\left.M_{c}=16.69\right)$. Greater differences in expressing cognitive anxiety and sports self-confidence were not found according to the type of sport (Table 6). 
TABLE 5

Gender differences in expressing sports anxiety.

\begin{tabular}{lrrrcc}
\hline & $M$ & $d f$ & \multicolumn{1}{c}{$M S$} & $F$ & \multicolumn{1}{c}{$p$} \\
\hline Cognitive anxiety & 152.553 & 1 & 152.553 & 5.306 & $\mathbf{. 0 2 4}$ \\
\hline Somatic anxiety & 94.599 & 1 & 94.599 & 3.072 & .083 \\
\hline Sports self-confidence & 84.633 & 1 & 84.633 & 3.221 & .076 \\
\hline
\end{tabular}

Legend: M - Mean; df - Degrees of freedom; MS - Mean square; F - Fisher's test of determining statistical singificance; $\mathbf{p}$ - Probabilitiy.

TABLE 6

Gender differences in expressing sports anxiety.

\begin{tabular}{lrrrrr}
\hline & $M$ & $d f$ & \multicolumn{1}{c}{$M S$} & \multicolumn{1}{c}{$F$} & \multicolumn{1}{c}{$p$} \\
\hline Cognitive anxiety & 11.393 & 1 & 11.393 & .374 & .543 \\
\hline Somatic anxiety & 140.494 & 1 & 140.494 & 4.646 & $\mathbf{. 0 3 4}$ \\
\hline Sports self-confidence & 1.016 & 1 & 1.016 & .037 & .847 \\
\hline
\end{tabular}

Legend: M - Mean; df - Degrees of freedom; MS - Mean square; F - Fisher's test of determining statistical singificance; $\mathbf{p}$ - Probabilitiy.

TABLE 7

Competitive anxiety and the level of sports success

\begin{tabular}{lccrcc}
\hline & $M$ & $d f$ & \multicolumn{1}{c}{$M S$} & $F$ & $p$ \\
\hline Cognitive anxiety & 199.661 & 1 & 99.830 & 3.500 & .035 \\
\hline Somatic anxiety & 348.893 & 1 & 174.446 & 6.222 & $\mathbf{. 0 0 3}$ \\
\hline Sports self-confidence & 278.250 & 1 & 139.125 & 5.748 & $\mathbf{. 0 0 5}$ \\
\hline
\end{tabular}

Legend: M - Mean; df - Degrees of freedom; MS - Mean square; F - Fisher's test of determining statistical singificance; $\mathbf{p}$ - Probabilitiy.

Differences in Expressing Competitive Anxiety in Relation to the Level of Sports Success

The results of MANOVA Analysis show significant differences in the intensity of somatic anxiety and sports self-confidence in relation to the level of sports success (Table 7). The differences were found between outstanding and ordinary sportsmen, whereas they were not confirmed on the sample of recreative athletes. Outstanding athletes are less stressed before performing, their intensity of somatic anxiety is rather low. Also, they have greater sports self-confidence compared to standard sportsmen (somatic anxiety $-M_{\mathrm{o}}=14.6, \mathrm{M}_{\mathrm{s}}=19.3$, sports self-confidence $\left.\mathrm{M}_{\mathrm{o}}=30.6, \mathrm{M}_{\mathrm{s}}=25.9\right)$.

\section{DISCUSSION}

Taking into account the fact that nowadays there is a stronger orientation onto the success in sports performance, researchers are greatly interested and oriented onto finding and establishing all the relevant factors which contribute to it (Pineda-Espejel et al., 2011; Behzadi et al., 2011). In this study the multidemensional construct of anxiety was used and it icludes somatic and cognitive anxiety as well as sports self-confidence. The findings show that the level of sports anxiety depends on several factors - certain personality traits, gender, type of sport, level of sports successful performance, etc.

The personality traits of sportsmen stand out as significant predictors of sports anxiety. Aggressiveness is an important negative predictor of somatic and cognitive anxiety but sports self-confidence is a positive predictor. The sportsmen who express this characteristic have an emotional predisposition for stormy, impulsive reactions and they often behave in intrusive and arrogant way with a strong will to dominate in every way (Smederevac et al., 2010). So it is not a surprising fact that their high level of self- 
-confidence and the lack of worries of the potential failure gives them unshakable faith. The findings of this research, as it was expected, state Neuroticism as an important predictor of cognitive anxiety. Moreover, the openness towards new experience also emerged as a significant predictor of cognitive anxiety. Neuroticism, more exactly, emotional instability, refers to the tendency of experiencing negative emotions, but the pure aspect of Neuroticism is actually Anxiety (Ibid), so the expected bond of these characteristics with sport anxiety was proved. Opennes to new experience, although it means curiosity, a wide range of interests, etc., if it is very outstanding, it also goes without saying, may be the leading factor to reach success or failure. As important predictors of sports self-confidence, Openness to new experience and Conscientiousness occupy the top position among the rest of the predictors. The person who has a lot of Conscientiousness may be described by these features: self-control, discipline, putting great effort into training, all of which will finally create greater self-confidence into his own personal skills and abilities. On the other hand, Openness to new experience may act as a negative predictor of self-confidence, implies lots of interests, constant pursuit for sensations, so it is hard to imagine such an athlete to be persistent in sports training and at the same time to direct his energy and interests solely onto sport. This trait may yield and contribute to the uncertainty of the athlete when he has a sports performance and has to be as fit as a fiddle.

Even though it may be assumed that there is a bond between the personal trait and adjoining state (for example: the trait and the state ox anxiety, such findings may be the consequence of the fact that $\mathrm{VP}+2$ measures the personal traits, while CSAI- 2 just the state of anxiety. The relations would have been more convincing if the personal trait of anxiety was measured.

According to our expectations and previous researches, women tend to have a higher level of cognitive anxiety (Humara, 1999; Pineda-Espejel et al., 2011). Women, more than men, evaluate the performing and competitive situation as threatening, not as a challenging one (Cassady \& Johnson, 2002), which raises the level of their cognitive anxiety. Researches also show the fact that psychological factors are far more important as the predictors of sporting achievements of sportswomen, compared to sportsmen (Matsumoto et al., 2000). However, it is important to emphasize here that the sample of examinees was not equalized in gender, there were 56 men and 34 women, therefore such a shortcoming should be corrected in future researches.
The individual sportsmen have a greater level of somatic anxiety compared to those who are inrolled in collective sports. The explanation for such results lies in divided resposibility which is shared among the team sportsmen, whereas the individual sportsmen feel the great pressure since they are alone responsible for the outcome of their performance. The leading sportsmen are less stressed before performing since they gained more sports self-confidence, so they also have a lower level of somatic anxiety, compared to standard, ordinary sportsmen. Top athletes achieve better results and that gives them more self-confidence. Researchers claim that sportsmen who see themselves as successful are at the same time, sure of their abilities so they are more self-confident and the symptoms of anxiety serve them as a welcome stimulus (Pineda-Espejel et al., 2011). On the sample of recreative athletes there were no differences found since they do not face competitive situations. Consequently, we may expect a low level of sports anxiety with recreative sportsmen. On the other hand, we must consider the fact that the examined sportsmenwere judging the level of their sports performance (outstanding/standard sportsmen/recreative athletes), as well as the fact that the sample was not equalized according to this variation (outstanding sportsmen -15 athletes, standard -60, recreative -15). Sportsmen with higher self-esteem, who consider themselves as outstanding, are naturally expected to have better results in sports performing and they do so. This research justified its starting point.

\section{CONCLUSION}

The results of this research are presented here in the attempt to explain sports anxiety not just to the scientists but also to sports workers, coaches and athletes. They give us a better understanding of this important phenomenonso they can help sportsmen and their coaches to recognize and prevent factors which influence the anxiety of sportsmen. All of this was done to improve the level of sports success. This research dealt with anxiety as a state, the suggestion for future explorations should refer onto understanding anxiety as a personal trait and examine its importance for sports success. We may assume that a sportsman with great self-confidence would be more successful in sports situations when it comes to competition. It would be useful to examine some other bonds among factors which are important for the self-esteem of athletes (for example the training style) and the sports success. Further researches in this field are indispensable to understand fully the way psychological factors influence the sports achievement. 
The main reason is to help athletes get rid of anxiety and eliminate all the frustrating factors while trying to realize best results and use their potentials.

\section{REFERENCES}

Behzadi, F., Hamzei, M., Nori, S., \& Salehian, M. H. (2011). The Relationship between goal orientation and competitive anxiety in individual and team athletes fields. Scholars Research Library, 2, 261-268.

Bridges, A., \& Knight, B. (2005). The role of cognitive and somatic anxiety in athletic performance. Hanover, Germany: Hanover College.

Craft, L. L., Magyar, T. M., Becker, B. J., \& Feltz, D. L. (2003). The relation between the competitive state anxiety inventory-II and sport performance: A meta-analysis. Journal of Sport and Exercise Psychology, 25, 44-65.

Dunn, J. G. H., \& Dunn, J. C. (2001). Relationships among the sport competition anxiety test, the sport anxiety scale, and the collegiate hockey worry scale. Journal of Applied Sport Psychology, 13(4), 411-429. doi: 10.1080/104132001753226274

Feltz, D. (1988). Self-confidence and sport performance. Exercise and Sport Science Reviens, 16, 423-457. doi: 10.1249/00003677198800160-00016

Gershuny, B. S., \& Sher, K. J. (1998). The relation between personality and anxiety: Findings from a 3-year prospective study. Journal of Abnormal Psychology, 107(2), 252-262. doi: 10.1037/0021843X.107.2.252; PMid:

Gould, D., Petlichkoff, L., \& Weinberg, R. S. (1984). Antecedents of temporal changes in, and relationships between CSAI-2 subcomponents. Journal of Sport Psycbology, 6, 289-304.

Hardy, L. (1996). A test of catastrophe models of anxiety and sports performance against multidimensional anxiety theory models using the method of dynamic differences. Anxiety, Stress and Coping. 9, 69-86.

Hardy, C., \& Crace, K. (2009). Dealing with precompetitive anxiety. Sport Psychology Training Bulletin, 3513-3517. doi: 10.1080/10615809608249393

Humara, M. (1999). The relationship between anxiety and performance: A cognitive behavioral perspective. The Online Journal of Sport Psychology, $1,1-14$.

Jones, G., Swain, A. B. J., \& Cale, A. (1991). Gender differences in precompetition temporal patterning and antecedents of anxiety and selfconfidence. Journal of Sport and Exercise Psychology, 13, 1-15.

Kirby, R. J., \& Liu, J. (1999) Precompetition anxiety in chinese athletes. Perceptual and Motor Skills, 88(1), 297-303. doi: 10.2466/pms.1999.88.1.297

Knežević, G., Radović, B., \& Opačić G. (1997). Evaluacija "Big Five" modela ličnosti kroz analizu inventara ličnosti NEO PI-R [Evaluation of the »Big Five« model of personality through analysis of personality inventory NEO PI-R]. Psibologija, 30(1-2), 7-40.

Komarraju, M., Karau, S. J., \& Schmeck, R. R. (2009). Role of the Big Five personality traits in predicting college students' academic motivation and achievement. Learning and Individual Differences, 19(1), 47-52. doi: 10.1016/j. lindif.2008.07.001

Marić, M. (2010). Osobine ličnosti, životni događaji i anksioznost adolescenata [Personality traits, life events and adolescent anxiety]. Primenjena psibologija, 19(1), 39-57.

Martens, R., Burton, D., Vealey, R. S., Bump, L. A., \& Smith, D. E. (1990). Development and validation of the competitive state anxiety inventory-2. In R. Martens, R.S. Vealey, \& D. Burton (Eds.), Competitive Anxiety in Sport (pp. 117-190). Champaign, IL: Human Kinetics.

Matsudaira, T., \& Kitamura, T. (2006). Personality traits as risk factors of depression and anxiety among Japanese students. Journal of Clinical Psychology, 62(1), 97-109. doi: 10.1002/ jclp.20215; PMid: 16287151

Matsumoto, D., Takeuchi, M., Nakajima, T., \& Iida, E. (2000). Competition anxiety, self-confidence, personality and competition performance of american elite and non-elite judo athletes. Research Journal of Budo, 32(3), 12-21.

Middeldorp, C. M., Cath, D. C., van den Berg, M., Beem, A. L.,van Dyck, R., \& Boomsma, D. I. (2006). The association of personality with anxious and depressive psychopathology. In T. Canli, (Ed.), Biology of personality and individual differences (p.p. 254-272). New York, NY: The Guilford Press.

Pineda-Espejel, A., López-Walle, J., Rodríguez, J. T., Villanueva, M. M., \& Gurrola, O. C. (2011). Precompetitive Anxiety and Self-confidence in Pan American Gymnasts. Science of Gymnastics Journal, 5(1), 39-48.

Smederevac, S., Mitrović, D., \& Čolović, P. (2010). Velikih pet plus dva [The big five plus two]. Belgrade, Serbia: Centar za primenjenu psihologiju. 
Tran, X. (2012). Football Scores on the Big Five Personality Factors across 50 States in the U.S. Sports Medicine \& Doping Studies, 2(6), 1-5.

Vujanović, S., \& Tišma, M. (2011). Povezanost kompetitivne anksioznosti i efikasnosti sportista
[Correlation between competitive anxiety and efficacy of athletes]. Aktuelno u praksi, 23(10), 31-41.

Received: Mart 12, 2014

Revision received: May 22, 2014

Accepted: Jun 26, 2013

Correspondence to:

Dejana Velikić, MA

Visoka škola strukovnih studija za obrazovanje vaspitača i trenera

Banijska 57

24000 Subotica

Serbia

Phone: 00381606338810

E-mail: dejana.velikic@gmail.com 